\title{
Annuity solutions in a low-yield environment
}

Received (in revised form): 28th July, 2000

\section{Elaine Flower}

has many years' experience of advising individuals on all areas of personal financial planning. She currently works for Marsh Financial Services Ltd, having transferred from William M Mercer Limited when MMC decided to merge their resources earlier this year. Elaine is a Chartered Accountant and after completing her accountancy training she gained experience in personal tax and financial planning while working for two major firms of accountants, before joining Mercer in 1987. \begin{abstract}
the following points:
- the annuity option

- planning options

- tax-free cash

- escalation in payment

- investment-linked annuities

- segmentation

- the future: is it drawdown?
\end{abstract}

Abstract Interest rates are historically low which has brought the question of fixing pension purchase through annuities to the top of the agenda.

However, there are no guarantees that rates will rise in the future. This paper looks at how annuities can be used, and where the risks of remaining in equities lie. It considers

This paper was first published in the Pensions Management Institute's Technical PMI News in September 1999.

Keywords: annuity; drawdown; risk; investment; planning; interest rates

Elaine Flower

(Marsh Financial Services Ltd, Havelock Chambers, Queens Terrace,

Southampton SO14 3PP

Tel: +44 (0)23 80318325 ; Fax: +44 (0)23 80318392 ; e-mail:

elaine.flower@marshmc. com)

\section{Introduction}

The ability for individuals to defer annuity purchase at retirement is a hot topic at present. The proposals for money purchase occupational schemes to offer this facility have been published. This adds to the well-established role of personal pensions in the 'drawdown' arena. The name has changed several times, so references to drawdown should read as Pension Fund Withdrawal technically.

Having the facility available does not necessarily mean that its use makes sense.
As with all sophisticated solutions, there is a place where the use of drawdown is a definite advantage. Many other times individuals may be swept along, not really understanding what they are doing, or why, simply because everyone else is doing it.

This development has come about because the current low yields available at retirement concern the industry, the government and the people, who perceive that their pensions are unfairly low taking historical data into account. It is worth taking a step back and 
reviewing the position: What is the real effect of a low-yield environment? What solutions are available within the annuity market? And where are the risks in relation to the choices available?

\section{The annuity}

In its simplest form an annuity is the exchange of a lump sum of money for a guaranteed future stream of income paid at predetermined intervals during the life of the annuitant. For a variety of reasons the purchase of an annuity is compulsory from a pension plan by age 75 or earlier depending on the specific terms of the scheme.

Other features have been added and some may now be compulsory, such as dependants' pensions or escalation in payment. These will all affect the cost of the annuity, but perhaps not the decision as to whether one is attractive or not because they are simply added on at the appropriate rate. More importantly in the assessment of the situation, the insurance company will take account of what return they can make on the money, what charges and profit they want from the contract and, of course, the life expectancy of the annuitant before determining the rate on offer.

If individuals had a choice between investing the pension fund personally, or buying an annuity, they would have two key issues to consider:

- Can they reasonably expect to live longer than the assumption built into the calculation of the rate offered by the insurance company?

- Can they invest at their personal tax rate more effectively than the assumption of growth built into the rate offered, at the same level of risk?

The other follow-on question from this analysis is then whether they are prepared to take a higher risk than that inherent within the contract. The traditional annuity route allows little scope for the individual to improve the position by adopting a higher risk:reward ratio.

Life expectancy can never be predicted accurately and therefore highlights one of the important risk factors. Do the individuals want to take the risk or do they want the insurance company to take it? With the establishment of impaired life annuities, and drawdown in particular, there may be a change in the costing of annuity products in the future. The cross-subsidies are gradually being removed by these methods.

The answer on the investment point is that there would be little scope at the point of purchase to improve the position even if greater flexibility were available. Where the personal investment route would be better is when things change at a later date. Once the traditional annuity is bought it is fixed and there is no room for flexibility to account for future actions, whereas with personal investment there is that opportunity.

At present there is no room for choosing whether to buy the annuity except through the drawdown route, and that is limited to a certain period of time. The decision has to be taken much earlier when the money is tied up in the pension plan altogether, ie the joining decision. However, all is not lost. There are several opportunities for using the annuity in a customised way to suit personal circumstances and objectives.

\section{Planning options}

Some of the planning options are not available in all money purchase schemes; the most flexibility is available 
Table 1: Example of current annuity rates and effect of escalation options

\begin{tabular}{lll}
$\begin{array}{l}\text { Male age } 65, \text { spouse age } 62, \\
£ 100,000\end{array}$ purchase price, no guarantee & Monthly in arrears $50 \%$ spouses pension \\
\hline Type of annuity & Initial pension & Reduction from level annuity \\
\hline Level annuity & 7260.00 & \\
$3 \%$ escalation & 5688.00 & $25 \%$ \\
$5 \%$ escalation & 4572.00 & $35 \%$ \\
$8.5 \%$ escalation & 2832.00 & $63 \%$ \\
RPI increases & 5652.00 & $26 \%$ \\
\hline
\end{tabular}

Source: Standard Life.

to personal pension holders. It is possible to transfer to a personal pension from an occupational scheme to benefit from some of these features if they are not directly available, but that is a whole topic in itself. The following comments should be read with this in mind.

\section{Tax-free cash}

In money purchase schemes it is almost always best to take the tax-free cash because it is simply paid from the fund without any sort of conversion factors applying. If an individual really wants a full pension, then they have the option to purchase a PLA (purchased life annuity). The PLA incorporates income tax benefits in that a part of the income is treated as a capital return and is not taxable. So, only a part of the income is taxable and it can often therefore provide a better pension than a CPA (compulsory purchase annuity).

If the cash is available from a defined benefit scheme the comparison is more complicated but still worth doing. Factors such as the commutation rate can be advantageous or not depending on the conversion factor. The possibility of discretionary increases being paid in the future only on non-commuted pension must also be taken into account in the assessment.

\section{Escalation in payment}

Choosing whether to buy a fixed level of escalation in payment where there is a choice is always a thorny issue. The choice can be a fixed percentage increase of, say, 3 per cent or 5 per cent, or a link to the RPI (Retail Prices Index). A level annuity will provide a higher starting income than an increasing pension from the same fund, because the increases cost a good deal of money.

It is possible to take a level annuity at outset, save the extra income generated and thereby fund the future increases personally from savings. Whether this makes sense depends on the personal tax rate of the individual, the level of risk they are prepared to take and their life expectancy. It can take 15 to 20 years to break even, which takes most people past their normal life expectancy if they retire at 65 .

However, there is often neither the information available nor the understanding of the recipient to make this case. Even with inflation reasonably under control the purchasing power of the pension will appear to erode. It is neither politically correct nor perhaps sensible to allow people to think they are getting worse off in retirement, and so the purchase of escalation has become a requirement for occupational pensions. There is more flexibility in personal pensions. 
Table 2: Timing of annuity purchase

\begin{tabular}{lrc}
\hline \multicolumn{2}{l}{ Based on purchase price of $£ 100,000$} & \\
\hline Year & Male 65 & Female 60 \\
\hline 1999 & $£ 8,332$ & $£ 6,553$ \\
1998 & $£ 9,723$ & $£ 8,108$ \\
1997 & $£ 9,821$ & $£ 8,189$ \\
1996 & $£ 10,351$ & $£ 8,740$ \\
1995 & $£ 10,250$ & $£ 7,654$ \\
1994 & $£ 9,544$ & $£ 9,583$ \\
1993 & $£ 11,603$ & $£ 10,896$ \\
1992 & $£ 12,046$ & $£ 12,167$ \\
1991 & $£ 14,046$ & $£ 12,796$ \\
1990 & $£ 14,653$ & \\
\hline
\end{tabular}

Source: Chartered Insurance Institute "Planning for a Flexible Retirement"/Scottish Equitable.

\section{Investment-linked annuities}

Annuities are now available with both unit-linked and with-profit investment options. The broad principle is that the annuitant chooses the projected investment return within the contract and then the figures are adjusted to account for the actual performance. The annuity may fall or rise depending on how aggressive an assumption was made.

Certain individuals want to skew the timing of the annuity value and will therefore deliberately choose a very high or low assumed growth rate. In particular, a high initial rate can be used to increase the initial income at the expense of later payments.

Investment-linked annuities do give some scope for benefiting from future investment returns, while having a base line of income on which the annuitant can depend. Purists may say that the two elements should be kept apart and perhaps that is right for large funds.

One of the major benefits of the investment-linked approach is that the mortality drag problems associated with not buying an annuity are removed. Mortality drag is the gain in the annuity that arises from cross-subsidy in calculation of the rates, from which drawdown participants cannot benefit.
This is because the benefit is built in at outset.

\section{Segmentation}

Where it is possible to segment the pension, the annuitant has the range of options available, and various combinations. At its simplest level the pension can be taken in stages, with each segment set up on a different basis. For example, an early segment may be set up on a level basis to get the maximum income as soon as possible, with escalation in payment only being purchased at a later date.

With a large fund there would always be the possibility of buying different elements to balance the risks. For example, an individual may decide that they want a high level of income initially while they are active, falling away as they get older. A with-profit annuity assuming a high bonus rate will provide a high level of initial income which could fall in future. A level annuity on a single life basis will have a similar effect, providing a high level of initial income which will fall in real value as inflation takes its toll. Both could be purchased with different segments, perhaps with a remaining 
amount left to buy an escalating pension at a later date.

Many insurance companies now offer formal phased arrangements but they tend to be on a fixed basis. By arranging the phasing on an individual basis there is much more flexibility but the costs of advice do rise. Whether this is good value depends on the objectives of the exercise and how much flexibility is needed.

This type of planning needs reasonably large sums to be available, and it could be argued that it is unnecessary to make it so complicated. However, each of these types of annuity carries different risks and the combination could satisfy the individual's desire to balance those risks. It also gives an opportunity to make decisions at different times as circumstances dictate. It is also worth remembering that all the annuity options are available to participants in drawdown contracts, so they can combine the annuity flexibility with the full investment options.

\section{The future}

So is it just a case of trying to keep things uncommitted until interest rates rise again or do we need sophisticated solutions going forward? The indications are that the days of high interest rates and high inflation are gone for the medium term, and as we move towards monetary union in Europe we must keep it that way. The relative position of pensioners will not necessarily be that bad because costs are under control and pensions will therefore retain their purchasing power. The risk for the individual is that it is not maintained.

Certainly no adviser talking to an individual about drawdown would suggest using it just for the purpose of trying to beat interest rates without addressing the risks involved. There are other reasons which can be more important. The major reason for someone who understands and wants the investment flexibility of a drawdown contract not actually finding it to be suitable at present is the current requirement to purchase an annuity at age 75 . This is anomalous to the principles of managing the resources sensibly and many expect it to be withdrawn in the near future.

The withdrawal of the 75 age limit for drawdown would make it possible to have greater freedom to invest for the long term, and in turn would make it more suitable in a larger number of cases. Certainly the risks could be managed more effectively because the investment strategy would not have this artificial cut-off point.

In the meantime, there are annuity solutions which can be used imaginatively where the security of knowing part or all of the outcome is preferred. 